\title{
As configurações do futebol brasileiro: análise da trajetória de um treinador
}

\author{
Guilherme Augusto Talamoni" \\ Flávio Ismael da Silva Oliveira** \\ Dagmar Hunger ${ }^{* * *}$
}

\begin{abstract}
Resumo: No presente artigo objetivou-se analisar a trajetória de um Treinador de futebol, levantando informações que possam auxiliar na discussão sobre formação e atuação profissional em Educação Física e Esportes. A pesquisa, de caráter qualitativo, utilizou História de Vida como método de coleta de dados. Para elucidar e articular questões abordadas utilizou-se conceitos da teoria sociológica de Norbert Elias. A partir da trajetória expressa e da proposta de configuração de Elias, concluímos que a figura do Treinador se formou em decorrência das relações de interdependência estabelecidas no âmbito dos grupos específicos o qual fez parte, enriquecidas pela formação acadêmica.
\end{abstract}

Palavras-chave: Treinador. Futebol. Formação profissional.

\section{INTRODUÇÃO}

$\mathrm{Na}$ condição de uma das figuras centrais do fenômeno esportivo, o treinador possui significativo destaque, principalmente no futebol, como um dos principais responsáveis pela sua dinâmica. Com responsabilidade no desenvolvimento e desempenho competitivo das equipes, Elias e Dunning (1992) defendem que o treinador tem a função de preparar seus jogadores levando em consideração a estrutura do jogo e as relações que se estabelecem tanto na preparação desportiva quanto na própria competição. Porém, com a

\footnotetext{
"Professor do Programa de Pós-graduação em Ciências da Motricidade, Instituto de Biociências, UNESP, Rio Claro, SP, Brasil. E-mail: gtalamoni@gmail.com

"Professor do Programa de Pós-graduação em Ciências da Motricidade, Instituto de Biociências, UNESP, Rio Claro, SP, Brasil. E-mail: ftima@fc.unesp.br

"'-Professora do Departamento de Educação Física, Faculdade de Ciências, UNESP, Bauru, SP, Brasil. Programa de Pós-graduação em Ciências da Motricidade, Instituto de Biociências, UNESP, Rio Claro, SP, Brasil. E-mail: dag@fc.unesp.br
} 
função de interpretar o jogo como uma "configuração dinâmica" de jogadores, este deve "manter-se distanciado e reflectir sobre as características e regularidades destas configurações enquanto tais" (ELIAS; DUNNING, 1992, p. 289). Para isso, deve atuar embasado em uma série de conhecimentos e experiências específicos.

Considerando o contexto histórico do futebol brasileiro constatase facilmente a inserção de ex-jogadores nos quadros técnicos de muitos clubes (MARTURELLI JUNIOR, 2002; THIENGO, 2011), bem como de treinadores com ou sem formação específica. Diante da relevância do esporte no Brasil e no mundo e da limitação de estudos abordando esse tema, torna-se cada vez mais evidente a necessidade de pesquisas voltadas à investigação da formação e atuação de treinadores (JONES; ARMOUR; POTRAC, 2003, FEITOSA; NASCIMENTO, 2006, BENITES; BARBIERI; SOUZA NETO, 2007; CUNHA et al., 2010; THIENGO, 2011), e da formação profissional no campo da Educação Física e Esportes (BETTI; MIZUKAMI, 1997).

A partir desse cenário constituído, pouco se sabe a respeito das configurações relacionadas à formação e atuação profissional de treinadores de futebol. A idéia de configuração proposta por Norbert Elias (1970) está relacionada às estruturas que constituem a sociedade, formadas pelas relações de interdependência entre os indivíduos que estão simultaneamente inseridos em um meio social e são orientadas e unidas umas as outras de diversas maneiras. Assim, cada indivíduo dessa estrutura influencia e é influenciado pelas estruturas que são exteriores (formadas também por indivíduos) em diversos níveis. As pessoas

[...] através das suas disposições e inclinações básicas são orientadas umas para as outras e unidas umas as outras das mais diversas maneiras. Estas pessoas constituem teias de interdependência ou configurações de muitos tipos, tais como famílias, escolas, cidades, estratos sociais ou estados. Cada uma dessas pessoas constitui um ego ou uma pessoa, como muitas vezes se diz numa linguagem reificante. Entre essas pessoas colocamo-nos nós próprios. (ELIAS, 1970, p. 15). 
Dessa forma, é importante entender as configurações e as relações que se deram durante a trajetória de um indivíduo para compreender as forças que o levaram a se estabelecer em sua profissão (ELIAS, 1970, HUNGER; ROSSI; SOUZA NETO, 2011). Baseado na proposta de Elias (1970), é possível evidenciar tais configurações que permeiam processos de formação e atuação profissionais ao longo da trajetória de um treinador de futebol, bem como esboçar possíveis configurações do futebol brasileiro. Assim, o objetivo do presente estudo foi analisar a trajetória de um treinador de futebol e acessar, a partir de suas experiências, relações de interdependência relevantes para sua formação e atuação profissional.

\section{Processo Metodológico}

Para Pereira (2006), a carreira de um profissional é resultado de um fenômeno multidimensional e complexo. Seu desempenho depende de fatores como atitudes, crenças, conhecimentos, competências, comportamentos e práticas que influenciam na maneira que enxerga o mundo e a profissão. Por conta disso, o estudo desse profissional deve considerar as experiências de vida advindas das dimensões sociais, morais, psicológicas, políticas, pedagógicas, entre outras.

Assim, respeitando o caráter qualitativo da pesquisa, optou-se pelo método de "História de Vida", com a coleta do depoimento realizada por intermédio de uma entrevista semi-estruturada de caráter autobiográfico. Neste tipo de abordagem o pesquisador busca levantar questões relacionadas à trajetória do entrevistado, transmitindo, além de fatos vivenciados, sentimentos e emoções, associando-os a situações do presente ou a situações que deseja compreender, atendendo aos objetivos da pesquisa (ALVESMAZZOTTI; GEWANDSZNAJDER, 1998).

Estudos que investigam a formação e atuação de treinadores, priorizando a perspectiva deles próprios, permitem compreender aspectos necessários na formação, colaborando para melhorar sua 
atuação profissional (CUNHA et al., 2010). Neste sentido, alguns trabalhos utilizam a História de Vida para compreender como os profissionais constroem suas carreiras, contribuindo para formação de treinadores de futebol (JONES; ARMOUR; POTRAC, 2003).

Além de investigar profissionais que se destacam em uma determinada área, realçando perspectivas, conhecimentos e competências relacionadas às variadas experiências e utilizadas em suas profissões, é possível analisar o entrevistado em profundidade, construindo uma reflexão sobre o seu processo de formação. Tomando consciência das estratégias, do caminho trilhado e dos momentos importantes ao longo da vida, identificamos a importância que profissionais dão aos conteúdos de sua formação (JONES; ARMOUR; POTRAC, 2003, PEREIRA, 2006) e como articulam conhecimentos obtidos com a prática profissional (PEREIRA, 2006), trazendo acréscimos ao entendimento do mesmo e ao conhecimento científico.

O sujeito $^{1}$ desse estudo, no momento da coleta do seu depoimento, aos 63 anos de idade, atuava como treinador em um clube da primeira divisão do Campeonato Paulista de 2010. Antes de iniciar a carreira atuou como jogador de futebol, passando por categorias de base e por equipes profissionais. Formou-se em Educação Física em 1974, ainda enquanto jogador profissional. Como treinador, dirigiu equipes nacionais de média e grande expressão, com passagens por clubes da Arábia Saudita, Emirados Árabes, Portugal e Japão, além de dirigir a seleção nacional de um país do Oriente Médio.

\section{FoRMAÇÃo E ATUAÇÃo PROFISSIONAL - DAS "PELADAS" À ÁREA TÉCNICA}

Desde cedo todo brasileiro aprende que o futebol é um dom nacional. Tal "sentimento" já estava formalizado no dia-a-dia da maioria das famílias brasileiras na década de 1950, proporcionando

\footnotetext{
${ }^{1}$ Para preservar sua identidade, não será feita referência ao seu nome.
} 
relações de cumplicidade e rivalidade entre as pessoas (PERDIGÃO, 1986). Foi nessa década que o futebol confirmou sua posição privilegiada para a nação e a tão sonhada hegemonia se estabeleceu a partir de 1958, quando o Brasil, jogando contra a Suécia, sagrouse Campeão Mundial de Futebol, com jogadores como Pelé, Garrincha, Zagallo, entre outros heróis e ídolos da nação. O primeiro, um garoto negro de origem pobre, símbolo da ascensão social, alcançou status de celebridade em uma época em que os meios de comunicação já difundiam informações em grande escala (FOSTER, 2002).

Frente à configuração presente, o futebol exercia fascinação na maioria das pessoas. Assim, no interior do Rio Grande do Sul, sob influência do pai, torcedor do Grêmio de Porto Alegre, aliada à facilidade da prática, o gostar do futebol se formalizou nas já disputadas "peladas", como principal opção para o entrevistado durante sua infância e adolescência.

Para Elias (1995), as escolhas do indivíduo resultam das diferentes configurações em que ele está inserido a partir de sua infância e evoluem de acordo com seu convívio social. As idéias, vontades e desejos são modelados a partir de todas as suas experiências, principalmente daquelas que se apresentaram no interior dos grupos em que conviveu ao longo de sua vida.

[...] você aprende a gostar do futebol porque era a única coisa que você podia ter na mão naquela época era uma bola e qualquer lugar era fácil de você jogar.

Então quando tinha o clássico Gre-Nal2 ${ }^{2}$, que ainda hoje é o maior evento do futebol do Rio Grande do Sul, a cidade se transformava. Os vizinhos, um provocando o outro, fazendo desfiles, às vezes com crianças, com animais vestido do próprio time [...].

\footnotetext{
${ }^{2}$ Termo utilizado para se referir ao confronto entre o Grêmio Foot-Ball Porto Alegrense e Sport Club Internacional, ambos clubes tradicionais da cidade de Porto Alegre, Rio Grande do Sul.
} 
Mesmo inserido em uma nova configuração na qual passou a trabalhar para auxiliar nas despesas familiares, não se afastou do futebol, e aos poucos as práticas se ampliaram.

[...] eu que estudava em um período e no outro período trabalhava vendendo pastéis, doces, sonhos, essas coisas, de porta em porta, nas oficinas, e eu não podia encontrar meus amigos no meio do caminho em um campinho, jogando, que eu largava tudo de lado e ia jogar.

Cansei de às vezes ajudar meu pai, que era pedreiro, até as cinco e meia da tarde, carregando balde de cimento, massa, tijolo, e a minha chuteira ia junto. E cinco e meia da tarde ele me liberava e eu ia correndo pro campo.

Com o futebol tão presente, a expectativa de ser jogador de futebol profissional já fazia parte do imaginário de muitos. Por conta disso, famílias, muitas vezes, depositam em um de seus membros, a esperança de que alcance sucesso no futebol em busca de melhores condições de vida, conforto e tranquilidade (SOUZA et al., 2008).

A presença e apoio do pai aliados à participação de jogadores famosos, principalmente nas partidas beneficentes, aumentavam sua vontade e demonstravam a "pressão social" exercida para que esse quadro se concretizasse. Assim, desde seus primeiros anos, as experiências advindas das configurações presentes despertaram o desejo de tornar-se jogador de futebol, e em parte, foram responsáveis pelo curso que tomou sua vida.

A partir desse desejo e do contexto iniciou sua participação na equipe juvenil do clube de sua cidade, quando realizou testes no Grêmio e Internacional. Estabeleceu-se nesse último, onde morou embaixo da arquibancada do Estádio dos Eucaliptos. Ao retornar a sua cidade mudou alguns planos devido à situação financeira familiar.

[...] quando eu retornei de Porto Alegre, tava com uns três dias de férias na minha cidade, e tinha meu padrinho que morava em Curitiba [...], e como nós 
éramos em sete na família ele resolveu dar um alívio na minha casa e eu acabei indo com eles pra Curitiba para trabalhar, estudar e ao mesmo tempo tentar a sorte no futebol [...] em 66, 67.

Em Curitiba, começou a treinar no então Esporte Clube Água Verde, que passou a se chamar Esporte Clube Pinheiros e atualmente Paraná Clube. Logo chamou a atenção dos dirigentes e começou a treinar com a equipe profissional, onde profissionalizou-se "mais ou menos em 1969, 1970". Atuando principalmente no meio campo, como volante ${ }^{3}$, iniciou sua carreira profissional.

Ter alcançado a condição de jogador profissional de futebol teve enorme significado em sua vida. Entretanto, apesar da realização do sonho nunca deixou de pensar em concluir os estudos, movido principalmente pelas dúvidas geradas pela situação de muitos jogadores que encerravam suas carreiras sem conquistarem no futebol uma situação financeira estável.

[...] quanto jogador que terminava de jogar, na época tinha sido campeão, na década de 60 , e você via os caras trabalhando de servente de pedreiro, de... sei lá, padeiro, de outras coisas, porque não tinham profissão.

Movido pelas incertezas, alimentou também o sonho de se tornar piloto de avião a jato. Concluiu os procedimentos na Base Aérea de Curitiba, restando apenas o exame médico. Porém, um dos diretores das categorias de base do Água Verde, que também era da Base Aérea, o fez desistir.

Ele olhou pra mim e disse: você acha que você vai ser piloto? Você vai jogar futebol muleque. Eu falei: Ué, mas seu Mário! Ele disse: Não. Você vai chegar lá, o médico vai dizer que você tem problema no joelho. [...] Cheguei lá, me reprovaram no exame, e eu fui jogar futebol.

\footnotetext{
${ }^{3}$ Posição de meio campo com características de marcação que normalmente tem a função de fazer a ligação entre a defesa e o ataque quando a equipe está com a posse de bola.
} 
Apesar da decisão as dúvidas permaneceram. Queria ter uma profissão. "O que eu vou ser, médico? Não, eu vou jogar futebol. Vou ser não sei o que... aí Educação Física". Em 1969 prestou vestibular e foi aprovado no curso superior de Educação Física em Curitiba. Solicitou aos dirigentes do clube liberação durante um período para assistir às aulas. Conciliando futebol e estudos, obteve o diploma em 1974. Nesse período teve a oportunidade de aproximar conteúdos da graduação com a atuação do seu treinador, facilitando a compreensão de questões relacionadas.

Você tá fazendo Educação Física, você entende um pouco de tática. Que a gente recebia isso lá na Universidade. A gente estudou o 4-4-2, o WM que na época a gente vinha estudando, enfim, teve uma noçãozinha básica de posicionamento. Obviamente quando vinha pra campo jogar eu sempre falava com o treinador, conversava nas palestras, e a gente tinha uma noção do que era um esquema tático.

Tudo vinha junto. Foi bem no meio da minha carreira. Por isso, talvez, eu tenha tido a felicidade, por exemplo, de aprender muita coisa que a Universidade me deu, trazendo pro futebol.

Tal aproximação permitiu a compreensão de questões táticas e metodológicas de treinamento. Um dos professores era responsável pela preparação da equipe na qual o entrevistado atuava como jogador, e levando para os treinos métodos discutidos na Universidade. Nesse momento, o treino no futebol começava a ser discutido no ambiente acadêmico, principalmente após o fracasso do Brasil na Copa do Mundo de 1966, quando evidenciou-se a necessidade de uma preparação física mais específica diante do "futebol força" apresentado pelos europeus. Com isso, a Seleção brasileira rompeu com as metodologias de treinamento até então aplicadas e, já durante a preparação para a Copa de 1970, constatou-se uma valorização e incorporação do conhecimento científico na preparação da equipe nacional. 
Esse quadro foi estabelecido pela Confederação Brasileira de Desportos (CBD), órgão responsável pela seleção, com a convocação dos professores, formados em Educação Física, Cláudio Coutinho e Carlos Alberto Parreira (SOARES; SALVADOR; BARTHOLO, 2004), para comporem a Comissão Técnica, fortalecendo os momentos político e histórico que se configuravam no Brasil. Logo profissionais com formação acadêmica começaram a ser mais valorizados para comporem os quadros técnicos dos clubes brasileiros.

Como destaca Elias (1995), nesse modelo em que o Treinador estava inserido observa-se a influência das pressões sociais exercidas, especialmente quando são consideradas as diferenças de poder, no caso, os jogadores companheiros de equipe, treinador, comissão técnica e professores da Universidade. Todos atrelados à configuração social influenciaram de alguma forma seus interesses.

Diante de um contexto no qual se evidenciam influências familiares, na formação da identidade do futebol praticado no Rio Grande do Sul, principalmente no que diz respeito ao estilo de jogo, considerado viril, era comum a formação de jogadores e treinadores comprometidos, disciplinados e responsáveis. Em decorrência dessa caracterização, da boa educação recebida, das experiências vivenciadas na infância e durante sua participação nas categorias de base, onde já atuava como capitão, reforçadas pelo desempenho acadêmico, sempre se dedicou aos treinamentos e apresentou bom comportamento e bom relacionamento com diretores, treinadores, jogadores e torcedores durante o período de jogador.

[...] a vida sempre foi muito regrada, obviamente eu tinha as minhas extravagâncias de vez em quando, como qualquer jovem, mas nunca interferiu dentro do meu trabalho. Eu nunca fui multado por chegar atrasado, nunca fui multado por indisciplina.

Com a transferência do treinador de sua equipe, na condição de jogador mais velho, com seu histórico de boa conduta, 
responsabilidade e formação superior, aos 27 anos foi convidado pelos dirigentes para assumir o cargo de treinador. Aceitou o desafio e casou-se com sua atual esposa no mesmo ano.

$\mathrm{O}$ fato de treinar uma equipe na qual os jogadores eram companheiros e amigos, consciente de que deveria deixar claro seu novo papel, levou-o a adotar uma postura mais "direcionada" à nova posição.

E quando eu assumi de treinador, alguns deles quiseram me testar. Eu simplesmente afastei. Falei: - Você tá fora. Ele falou: - Mas eu sou teu amigo, porra. A gente saia junto até outro dia e tal, agora você quer o quê? Eu falei: - Não quero ser, eu sou o seu treinador. Lá fora eu fui teu amigo e continuo teu amigo, aqui dentro do campo eu sou treinador, e você tem que me respeitar. E eu não quero você. Você pode sair, vai lá e conversa com a diretoria e acerta seu contrato lá e vê o que você quer. No outro dia, o cara veio, pediu desculpa na frente de todo mundo, pediu desculpa. Eu reintegrei. A partir daquele dia nunca mais tive problema com jogador.

Percebe-se que a configuração do modelo alterou-se para um modelo, definido por Elias (1970), como oligárquico, modificando os níveis de disputa, mesmo permanecendo interdependentes. Para o autor, dentro desse modelo, o nível mais alto (treinador) tem uma força maior e mais estável do que o nível mais baixo (jogadores). Entretanto, a interdependência impõe limitações até mesmo ao nível mais alto, permitindo essa disputa de poder. Controlada a situação, prosseguiu com seu trabalho. Quando assumiu a equipe ocupava, entre doze equipes, a $11^{\mathrm{a}}$ posição. Com uma série de vitórias disputou o quadrangular final.

Em sua atuação como treinador, viu a possibilidade de ascender dentro do futebol e alcançar resultados que como jogador não seriam mais possíveis. Dentro da nova profissão seria capaz de atender aos anseios relacionados ao esporte despertados a partir das experiências vividas desde a época de garoto, encontrando sentido em sua nova atuação (ELIAS, 1995). 
Motivado com a função de treinador, dedicou-se e com pouco tempo de trabalho atraiu olhares de grandes clubes, nos quais realizou ótimos trabalhos. Aos 28 anos surgiu uma proposta em uma equipe de Minas Gerais da Primeira Divisão do Campeonato Brasileiro. Pela campanha recebeu o "Troféu Treinador Revelação" desse ano, contrariando, por exemplo, o quadro ilustrado por Marturelli Junior (2002) no qual o treinador mais novo do Campeonato Brasileiro de 2001 possuía 36 anos. Na sequência, conquistou o Campeonato Estadual do Paraná e, três anos depois, o Estadual de São Paulo. Com o destaque e ascensão no Brasil, despertou interesse de clubes do exterior, indo trabalhar em um clube da Arábia Saudita. Em sua primeira temporada conquistou a Copa da Federação Árabe. Nos anos seguintes alternou temporadas no Brasil e Oriente Médio, clubes da Arábia Saudita e Emirados Árabes Unidos, onde dirigiu a Seleção local.

Mesmo sem conquistar a classificação para a Copa do Mundo, teve a experiência de dirigir uma seleção nacional, cargo que poucos treinadores conseguem ocupar. "Aprendi muito e apanhei muito lá e soube o que é treinar uma seleção."

Após a eliminação dirigiu clubes no Brasil e Oriente Médio, alcançando um título gaúcho e seu terceiro título da Copa da Federação Árabe. Retornou ao Brasil por mais três anos até surgir uma oportunidade no Japão. Disputou uma temporada e retornou ao Brasil, permanecendo por mais cinco anos até ir para Europa treinar uma equipe de Portugal. Após dois anos voltou ao Brasil, dirigindo clubes em campeonatos de elite estadual e nacional.

\section{EXPERIÊNCIAS E CONHECIMENTOS PARA ATUAÇÃO PROFISSIONAL}

Dentro de um quadro configuracional que envolveu toda construção da profissão de treinador, foram comuns disputas que emergiram das relações de interdependência entre todos os envolvidos no processo. Tais "disputas" influenciaram a formatação da trajetória do entrevistado, possibilitando a ele experiências e conhecimentos que deram mais autoridade no espaço em questão. 
Assim, diante dos objetivos determinados nesse estudo, procurou-se compreender quais experiências e conhecimentos foram fundamentais para atuação e manutenção de sua carreira.

Para auxiliar a compreensão dos apontamentos relevantes desse contexto, faz-se necessária nesse momento categorizar as relações entre "estabelecidos" e "outsiders" proposta por Elias e Scotson (2000). Os autores partem da análise e descrição de dois grupos que habitavam uma comunidade inglesa. O primeiro, denominado estabelecido, era formado por moradores que residiam no local há muito tempo, enquanto o segundo, os outsiders, por um grupo mais novo de residentes. As principais diferenças entre ambos os grupos ficavam claras quando o grupo estabelecido, ao determinar normas de condutas e regras sociais vinculadas aos costumes e tradições locais, estigmatizava o grupo outsider de moradores.

Considerando então a trajetória do entrevistado, foi possível determinar experiências e conhecimentos formalizados que respeitaram essa categorização. Tal como destacado anteriormente, é muito comum a presença marcante e privilegiada de treinadores com experiência enquanto jogador profissional nos quadros técnicos das equipes de futebol, sendo esses considerados estabelecidos. Já o grupo outsider está relacionado àqueles profissionais que não apresentam histórico como jogador e se apóiam principalmente no conhecimento acadêmico.

Seguindo então a ordem de relevância destacada pelo entrevistado, o principal fator que contribuiu para sua formação e atuação profissional foi o fato de ter sido jogador, o que sempre lhe garantiu a condição de atuar como treinador de futebol. No período de jogador vivenciou situações que sustentaram seus primeiros passos e o levaram a compreender alguns pontos essenciais.

[...] eu hoje se fosse um dirigente, eu antes de fazer um time de futebol, de gastar dinheiro com um time de futebol, eu ia montar primeiro uma estrutura. Hoje têm clubes que não têm centro de treinamento, não têm uma sala pra fazer trabalho de força. Às vezes o departamento médico é muito mal feito e a maioria não percebe o quanto isso prejudica o 
trabalho. Porque um jogador, que você paga pra ele um salário alto, e você não dá a ele uma condição pra que ele possa desenvolver um futebol bom dentro de campo, você tá jogando dinheiro fora [...] uma contusão, uma falta de alimentação bem adequada, um cuidado melhor com o jogador, isso aí vai refletir lá dentro de campo.

Associado às necessidades estruturais, o entrevistado reconhece a interdependência com os demais membros da Comissão Técnica e considera importante o conhecimento e mesmo a vivência de algumas funções. Com conhecimento mínimo do trabalho do preparador físico é possível adequar os treinamentos e evitar abusos. A mesma lógica se aplica às demais funções tais como roupeiro, segurança, auxiliar técnico e preparador de goleiros. Somente assim é possível planejar melhor, confirmando a compreensão de Marques (2000), para quem o treinador não deve apenas orientar jogos e sessões de treino, deve gerenciar recursos e estratégias baseados em conhecimentos científicos e práticos, e na capacidade de refletir sobre as possibilidades e condições de sua equipe.

[...] e eu conheço o trabalho do roupeiro... eu não fui roupeiro, mas conheço. Eu conheço o trabalho do segurança, faz segurança no hotel. Conheço o trabalho do treinador de goleiro. Conheço o trabalho do preparador físico. [...]. Então eu só não fui presidente de clube ainda... Mas eu acho que teoricamente você tem na mão... eu tenho na mão hoje, desde o roupeiro até o presidente, a condição de fazer uma avaliação pra você de que dá pra ser feito no futebol e de que maneira dá pra ser feito.

Diferente, porém não desvinculado das questões estruturais apontadas, o aprendizado advindo da atuação dos treinadores com quem trabalhou, e das relações estabelecidas desses com os demais jogadores e treinadores durante os nove anos de carreira contribuíram em sua formação. Montagem da equipe, aplicação de treinamentos, escolha de sistemas de jogo e relação com os jogadores, permitiram que aproveitasse o melhor de cada um, facilitando a criação dos próprios métodos de trabalho, considerando sua personalidade, valores, ideais e objetivos. 
Quer dizer, são com treinadores que você aprende um pouquinho... o estilo deles de trabalhar. [...] mas você tem que criar seu estilo próprio. $\mathrm{Eu}$ acompanhei, vi o que esses treinadores faziam, a maneira de cada um, um mais ríspido, outro mais inteligente, um mais conversador, entende? [...] Mas, obviamente que isso aí te dava uma pequena parte, mas o resto você tem que ter personalidade, botar o teu eu lá dentro.

Mesmo com todos os aspectos positivos elencados pelo entrevistado, Marques (2000) considera que as experiências adquiridas como atleta nem sempre resultam em boas experiências como treinador. Nesse contexto, cada vez mais a aquisição de novos conhecimentos é fundamental para se alcançar sucesso, tal como destaca Pereira (2006).

Desta forma, contrariando a ordem vigente na qual dificilmente constata-se a presença de jogadores profissionais que buscam uma formação acadêmica simultaneamente a sua atuação profissional, a Universidade teve uma parcela importante em sua formação, segundo o seu ponto de vista.

Diante das tarefas específicas ele considera positivos os conhecimentos adquiridos e construídos durante o Curso de Educação Física. Como apresentado por Soares, Salvador e Bartholo (2004), nesse momento histórico o conhecimento cientifico já vinha ganhando espaço no futebol brasileiro, e a maioria dos clubes já passavam a valorizar uma formação profissional específica.

[...] dentro da Universidade você fazia um pouco de cada matéria, basquete era uma partezinha só, vôlei, futebol, natação, primeiros socorros, enfim... abrange tudo né? [...] Eu acho que deveria hoje, por exemplo, o cara que quer basquete, então ter pro cara um aprofundamento maior naquela área. Eu não sei se já começou hoje. Então eu acho que já teria que ter dentro da Universidade uma... Eu quero ser treinador de futebol, então preparar o cara pra ser o treinador de futebol. E não ele ter que dividir com o basquete, com o vôlei. Afunilar... por exemplo, o que você quer ser? Como o médico... Eu quero ser

Movimento, Porto Alegre, v. 19, n. 01, p. 73-93, jan/mar de 2013. 
ortopedista. E o cara vai especializar, a especialização é em ortopedia. Eu acho que deveria formar um profissional mais pra área que ele deseja atuar. Então eu tenho conhecimento de natação, vôlei, basquete tudo eu tinha. Mas eu encaminhei só pro futebol, eu fui pra dentro do campo.

Como se pode perceber, as forças presentes na configuração do curso superior em Educação Física, não estavam voltadas à formação específica, o que limitou a relação com sua atuação profissional. Como declarado, apenas algumas disciplinas fizeram sentido e tinham relação por conta de suas experiências em outras configurações, e foram direcionadas para satisfazer os seus interesses. Nesse sentido, aqueles que não vivenciaram experiências como jogador encontram mais dificuldade para transferir conhecimentos adquiridos na graduação para a prática profissional. Esse seria é um dos motivos que colaboram para a depreciação dos profissionais oriundos apenas do universo acadêmico (outsiders).

Apesar da importância direcionada ao conhecimento acadêmico, o entrevistado, tal como defendem Feitosa e Nascimento (2006) e Hunger e Rossi (2010), deixa claro que a formação superior permite uma atuação generalizada do profissional, e muitas vezes não atende às expectativas no que se refere à preparação para o mercado de trabalho.

No caso do entrevistado, mesmo concluído o curso de Educação Física, mantinha a posição de estabelecido devido ao acumulo de experiências como jogador profissional. Essa posição permitiu a ele aceitar o comando da equipe na qual atuava como jogador, bem como sustentar os desafios iniciais da carreira.

Desde o início deparou-se, agora de outra perspectiva, com um quadro configurado que permitiu construir e manter-se na carreira. A quantidade considerável de partidas e resultados nas inúmeras competições, as preparações técnica e tática constantes, as evoluções no campo da preparação física e tática; as mudanças frequentes das equipes e clubes; a influência e desgaste das relações com jogadores, torcedores e mídia permitiram compreender alguns 
fatores importantes para atuação do treinador esportivo. Aprendeu "dentro de campo" a distinguir entre variáveis a serem reforçadas e ignoradas. "[...] o aprendizado, ele veio de dentro do futebol."

A atuação no exterior, independentemente das experiências no Brasil, recebeu atenção especial. Acessar outras configurações culturais, estilos diferentes de jogos, clubes mais estruturados e expectativas distintas das que estava habituado, principalmente por comandar uma Seleção durante uma Eliminatória de Copa do Mundo, ampliaram seus novos "olhares" para carreira.

Você vai no Japão. [...] tem três massagistas que acompanham a delegação. Antes do jogo os caras vão pro ofurô, pra sauna fazer massagem. E tira deles pra você ver. Os caras não correm no outro dia. Se deixar eles correm. Como é que pode? Se você... aqui no Brasil proíbe esse relaxamento. E lá os caras estão acostumados com relaxamento. Como é que você vai fazer? Eu fiquei maluco lá. Eu tive problemas de brigar com o fisioterapeuta. [...] jogadores fazendo musculação em halteres com dor nas costas. E eu fui proibir e tive a maior briga. Cultura. Se você não adaptar, como você vai trabalhar na Arábia Saudita se você não deixar o cara comer com a mão?

De maneira resumida, durante os 34 anos como treinador, reconheceu uma série de modificações dentro das configurações do futebol, e a partir das experiências vivenciadas em sua trajetória foi possível se adequar a elas e obter um balanço altamente positivo de sua carreira. Devido ao seu comprometimento e seriedade no trabalho, na maioria dos clubes, recebeu mais de um convite para dirigir a equipe.

Eu to trabalhando [...] é como eu digo, as pessoas vem e falam: Ah, mas você tem sessenta e poucos anos, já tá ultrapassado. Pelo contrário! Eu passei várias gerações. [...] passei umas quatro, cinco gerações, e com todas elas eu trabalhei, sem problema nenhum. Quer dizer, eu tive que evoluir, certo? Porque eles mudaram. O perfil mudou, o 
perfil mudou. E com todas as gerações eu consegui trabalhar... E graças a Deus eu estou no mercado por causa disso. Estou a 34 anos no mercado e continuo no mercado justamente porque eu evolui junto $[\ldots]$.

\section{Considerações FINAIS}

A abordagem adotada nesse estudo possibilitou identificar as relações que contribuíram no processo de formação e atuação profissional do entrevistado. A partir do método de "História de Vida" foi possível identificar as configurações presentes em sua trajetória e as características das relações que lhe proporcionaram se tornar treinador de futebol e atuar na profissão durante todos esses anos.

Diante de sua trajetória, podemos salientar que foram vastas as experiências que determinaram suas escolhas e direcionaram sua vida. Durante a análise identificamos pontos relevantes para compreensão das configurações que o cercaram. Podemos perceber que as forças presentes desde a sua infância foram determinantes para ele se envolver sistematicamente com o futebol e se tornar jogador profissional. Entretanto, sabia que dificilmente se tornaria um jogador reconhecido nacionalmente e buscou na formação superior uma alternativa, caso encerrasse sua carreira. $\mathrm{O}$ fato de sempre demonstrar boa conduta e liderança fez com que os diretores do clube em que era jogador o considerarem como uma boa opção para ocupar o cargo de treinador da equipe. Dessa forma, evidenciase que as relações estabelecidas, principalmente nos modelos de configuração do futebol, proporcionaram condições para que construísse uma carreira como treinador.

Para o entrevistado, os conhecimentos mais importantes para sua atuação foram aqueles adquiridos a partir de suas experiências enquanto jogador e durante sua carreira como treinador. As situações que emergiram das relações de dentro do futebol, em sua opinião, contribuíram para se estabelecer profissionalmente, atuando por mais de 30 anos. Os conhecimentos advindos de sua formação superior em Educação Física também foram valorizados por ele. A partir 
deles passou a ter um olhar científico sobre o futebol e permitiu aceitar as mudanças com mais facilidade, justamente no momento em que profissionais com formação acadêmica começavam a ter força no futebol. Porém, no decorrer de sua trajetória fica claro a importância de ter sido jogador, e como esse histórico influencia em sua profissão, assumindo mais autoridade nas configurações em que ele esteve inserido.

Neste sentido, esperamos que esse estudo contribua para discussões acerca da formação e atuação profissional de treinadores de futebol, já que esta se apresenta como uma atividade complexa. No esporte, assim como em todos os outros domínios da atividade humana, novos conhecimentos e descobertas surgem a todo o momento (PEREIRA, 2006), contribuindo para criar modificações e novas relações dentro das configurações do futebol. Por conta disso, sugerimos novos estudos voltados à análise da "História de Vida" de treinadores de futebol, assim como de outros profissionais envolvidos com a preparação de equipes esportivas, pois, para Elias (1970), a "tarefa da pesquisa sociológica é tornar acessíveis à compreensão humana estes processos cegos e não controlados, explicando-os e permitindo às pessoas uma orientação (p. 168). 
The configurations of brazilian soccer: trajectory analysis of a coach

Abstract: The present article is set to analyze the career of a soccer coach, highlighting information that may be assist in the discussion on graduating and professional actuation in Physical Education and Sports. The research, qualitative, used Life History as a method of data collection. To elucidate and articulate issues raised was used concepts from sociological theory of Norbert Elias. From the explicit path and the proposed configuration of Elias, we conclude that the figure of the trainer was formed as a result of interdependence established within the specific groups which took part, enriched by the academic. Keywords: Coach. Soccer. Professional actuation.

\section{Las configuraciones del fútbol brasileño:} análisis de la trayectoria de un entrenador

Resumen: En el artículo, el objetivo es analizar la trayectoria de un entrenador de fútbol levantando informaciones que puedan ayudar en la discusión sobre la formación y actualización profesional en Educación Física y Deportes. La investigación, de carácter cualitativo, se utilizó Historia de la Vida como método de recopilación de datos. Para articular las cuestiones planteadas se utilizó conceptos de la teoría sociológica de Norbert Elias. Desde el camino y la configuración propuesta de Elias, llegamos a la conclusión de que el entrenador se formó como resultado de la interdependencia establecida en los grupos que han participado, enriquecido por el académico.

Palabras-clave: Entrenador. Fútbol. Formación Profesional. 


\section{REFERÊNCIAS}

ALVES-MAZZOTTI, Alda Judith; GEWANDSZNAJDER, Fernando. 0 método nas ciências naturais e sociais. São Paulo: Pioneira, 1998.

BENITES, Larissa Cerignoni; BARBIERI, Fabio Augusto; SOUZA NETO, Samuel. O futebol: questões e reflexões a respeito dessa "profissão". Pensar a Prática, Goiânia, v. 10, n. 1, p. 51-67, 2007.

BETTI, Irene Rangel; MIZUKAMI, Maria da Graça Nicoletti. História de vida: trajetória de uma professora de Educação Física. Motriz, Rio Claro, v. 3, n. 2, p. 108-115, 1997.

CUNHA, Gabriel Barros et al. Necessidades de formação para o exercício profissional na perspectiva do treinado de Futebol em função da sua experiência e nível de formação. Motriz, Rio Claro, v. 16, n. 4, p. 931-941, 2010.

ELIAS, Norbert. Introdução a sociologia. Lisboa: Edições 70, 1970.

Mozart: sociologia de um gênio. Rio de Janeiro: Jorge Zahar, 1995.

ELIAS, Norbert; DUNNING, Eric. A busca da excitação. Lisboa: Difel, 1992.

ELIAS, Norbert; SCOTSON, John. Estabelecidos e outsiders. Rio de Janeiro: Jorge Zahar, 2000.

FEITOSA, Wallacy Milton do Nascimento; NASCIMENTO, Juarez Vieira. Educação física: quais competências profissionais? In: SOUZA NETO, S.; HUNGER, D. (Org.). Formação profissional em educação física: estudos e pesquisas. Rio Claro: Biblioética, 2006. p. 87-98.

FOSTER, Kevin. O jogo bonito: futebol na Inglaterra e no Brasil nos anos 50 e 60 . ECO-PÓS, Rio de Janeiro, v. 5, n. 1, p. 12-26, 2002.

HUNGER, Dagmar Aparecida Cynthia França; ROSSI, Fernanda. Formação acadêmica em Educação Física: perfis profissionais, objetivos e fluxos curriculares. Revista Motriz, Rio Claro, v. 16, n.1, p. 170-180, 2010.

HUNGER, Dagmar Aparecida Cynthia França; ROSSI, Fernanda; SOUZA NETO, Samuel. A teoria de Norbert Elias: uma análise do ser professor. Educação e Pesquisa, São Paulo, v. 37, n. 4, p. 697-710, 2011.

JONES, Robyn; ARMOUR, Kathleen; POTRAC, Paul. Constructing expert knowledge: A case study of a top-level professional soccer coach. Sport, Education and Society, v. 8, n. 2, p. 213-229, 2003.

MARQUES, Antônio Teixeira. As profissões do corpo: o treinador. Revista Treinamento Desportivo, v. 5, n. 1, p. 04-08, 2000. 
MARTURELLI JUNIOR, Mauro. A organização do trabalho de treinadores de futebol: estratégias de ação e produtividade de equipes profissionais. Dissertação (Mestrado) - Universidade Federal de Santa Catarina, Florianopolis, 2002.

PERDIGÃO, Paulo. Anatomia de uma derrota. Porto Alegre/São Paulo: L\&PM, 1986.

PEREIRA, Antonino. A excelência em Educação Física e Desporto a partir de Histórias de Vida. In: PEREIRA, A. L.; COSTA, A.; GARCIA, R. P. (Org.). O desporto entre lugares: o lugar das Ciências Humanas para a compreensão do Desporto. Porto: Universidade do Porto, 2006.

SOARES, Antonio Jorge Gonçalves; SALVADOR, Marco Antonio Santoro; BARTHOLO, Tiago Lisboa. O "futebol arte" e o "planejamento México" na copa de 70: as memórias de Lamartine Pereira da Costa. Movimento, Porto Alegre, v. 10, n. 3, p. 113-130, 2004.

SOUZA, Camilo Araujo Máximo; VAZ, Alexandre Fernandez; BARTHOLO, Tiago Lisboa; SOARES, Antonio Jorge Gonçalves. Difícil reconversão: futebol, projeto e destino em meninos brasileiros. Horizontes Antropológicos, Porto Alegre, a. 14 , n. 30, p. 85-111, 2008.

THIENGO, Carlos Rogério. Os saberes e o processo de formação de futebolistas no São Paulo Futebol Clube. Dissertação (Mestrado) - Universidade Estadual Paulista, UNESP, Rio Claro, 2011.

Endereço para correspondência:

Guilherme Augusto Talamoni.

Rua Aparecida, № 14-36, bairro Jardim Santana,

Bauru, São Paulo.

CEP 17020-210.

Recebido em: 13.06.2012

Aprovado em: 17.11.2012 